\title{
Sodium hypochlorite treatment and light-emitting diode (LED) irradiation effect on in vitro gemmination of Oreorchis patens (Lindl.) Lindl
}

\author{
Kee Hwa Bae $\cdot$ Kyoung Hee Oh $\cdot$ Soo-Young Kim \\ Received: 4 March 2014 / Revised: 11 March 2014 / Accepted: 27 March 2014 \\ (c) Korean Society for Plant Biotechnology
}

\begin{abstract}
In this study, we investigated the effects of sodium hypochlorite $(\mathrm{NaOCl})$ and red or blue light-emitting diode (LED) light on embryo swelling and germination of Oreorchis patens (Lindl.) Lindl. A method for determining the swelling and protocorm formation in $O$. patens seeds through in vitro examination of immature seeds was established. $\mathrm{NaOCl}$ treatment of immature seeds was found to significantly enhance the extent of embryo swelling and protocorm formation in immature zygote embryos compared to those in the untreated controls. Additionally, the effects of white fluorescent light, and red and blue LED lights on embryo swelling and protocorm formation in in vitro cultured seeds were examined and compared to the conditions with or without $\mathrm{NaOCl}$ treatment. The most suitable light for embryo swelling and protocorm formation was the red LED light.
\end{abstract}

Keywords Germination, Medium, Orchid, Oreorchis patens

\section{Introduction}

Oreorchis patens (Lindl.) Lindl. belongs to the Orchidaceae and is distributed across East Russia (Amur, Kamchatka, Sakhalin, and Ussuri), China, Japan, and Korea (Lee and Choi 2006). It commonly grows in temperate deciduous forest margins, thickets, grassy places, shaded places, and along valleys in the main ranges of Baek-du-dae-gan (Lee and Choi 2006). This plant produces scapes $(30-50 \mathrm{~cm}$ tall) from May to July, each bearing 20-35 whitish-yellow flowers (7-15 mm long; 1.5-3 mm diameter) (Lee 2006). In vitro seed culture techniques of various orchid species have been widely used for its conservation and propagation

K. H. Bae $\cdot$ K. H. Oh $\cdot$ S.-Y. Kim $(\bowtie)$

National Institute of Biological Resources, 42 Hwangyeong-ro, Seo-gu, Incheon, 404-708, Republic of Korea

e-mail: sy7540@korea.kr
(Stewart and Kane 2006a; Stewart and Kane 2006b; Stewart and Kane 2007; Bae et al. 2009; Dutra et al. 2009; Suzuki et al. 2009; Bae et al. 2010; Bae and Choi 2013). Although this approach has been used for a long time, reports on in vitro germination of orchid species are limited, despite its large number of species.

It has been previously reported that sodium hypochlorite (NaOCl) treatment, a common method for disinfecting plant materials, is highly effective in stimulating in vitro germination of Oreochis coreana seeds (Bae et al. 2013). The effectiveness of seed disinfection using $\mathrm{NaOCl}$ and calcium hypochlorite $\left(\mathrm{Ca}(\mathrm{ClO})_{2}\right)$ solution to stimulate orchid seed germination has also been reported in other species (Malmgren 1996; Miyoshi and Mii 1998; Bae et al. 2009; Bae et al. 2010; Bae and Choi 2013). The mechanism underlying this stimulatory effect on orchid seed germination is not well understood (Harvais and Hadley 1967).

Light-emitting diodes (LEDs) have recently developed as an alternative light source for plant culture systems. They have several advantages compared to conventional light sources, including their wavelength specificity and narrow bandwidth (Bula et al. 1991; Hoenecke et al. 1992). LEDs have been used for studies on chlorophyll biosynthesis in wheat (Tripathy and Brown 1995), stem elongation and leaf expansion in lettuce (Hoenecke et al. 1992), disease development in pepper and cucumber (Schuerger and Brown 1994), and photosynthesis in kudzu (Tennessen et al. 1994).

However, to date, no effort has been made to develop a protocol for in vitro propagation or conservation of $O$. patens. This study aimed to describe seed germination and embryo development in $O$. patens and evaluate and establish a method for in vitro culture of immature seeds of $O$. patens. 


\section{Materials and methods}

Plant materials and culture conditions

The fruits of Oreochis patens were collected immediately before dehiscence from a single population near the Hambaek Mountain (Kangwon Province) in late September 2013 (voucher specimen, VP0000288327 and seed number, GR0000255167). Following collection, the seeds were immersed in deionized sterile water and agitated for $30 \mathrm{~min}$. The seeds were then treated with $30 \mathrm{ml}$ of $1 \% \mathrm{NaOCl}$ in deionized water $(\mathrm{v} / \mathrm{v})$ for $30 \mathrm{~min}$, followed by three $30 \mathrm{~s}$ rinses in deionized sterile water. All media were supplemented with $20 \mathrm{~g} / \mathrm{L}$ sucrose and the $\mathrm{pH}$ was adjusted to 5.5 with $0.1 \mathrm{M} \mathrm{KOH}$ before the addition of $3.0 \mathrm{~g} / \mathrm{L}$ gelrite. The media were autoclaved at $117.7 \mathrm{kPa}$ at $121{ }^{\circ} \mathrm{C}$ for $15 \mathrm{~min}$. The cultures were maintained in a growth room at $20 \pm 2^{\circ} \mathrm{C}$.

Effects of $\mathrm{NaOCl}$ and culture medium on embryo swelling and seed germination

Mature capsules were sterilized in $1 \% \mathrm{NaOCl}$ for $30 \mathrm{~min}$ and then rinsed three times with sterile water. The seed capsules were then cleaved using a scalpel blade and the seeds were scraped. The seeds were treated with $1 \%$ $\mathrm{NaOCl}$ for $30 \mathrm{~min}$. The seeds were then left in the final rinse water until their transferred to Phytomax Orchid Maintenance (POM) medium (P6668, Sigma Co. Ltd., USA) and Seed Germination Maintenance (SGM) medium (P6543, Sigma Co. Ltd., USA). Two basal media were used in this study: POM and SGM media without plant growth regulators. Embryo swelling was defined as an increase in size of at least twice the original size and the formation of a protocorm. The number of swollen embryos and the diameters of the embryos were recorded at 2 week intervals by examining under a microscope.

Effects of $\mathrm{NaOCl}$ and light emitting diodes (LEDs) on embryo swelling and seed germination

The seeds were treated with $1 \% \mathrm{NaOCl}$ for $30 \mathrm{~min}$. and were then left in the final rinse water until these were transferred to the POM medium. Cultures were incubated in growth chambers (Sejong Scientific, Korea) at $25^{\circ} \mathrm{C}$ and $60 \%$ relative humidity. The seeds were subjected to three different cultures treatments by using the following sources of illumination : (1) fluorescent light, (2) red LED (peak wavelength: $660 \mathrm{~nm}$ ), (3) blue LED (peak wavelength: $450 \mathrm{~mm}$ ). The duration of lighting for all treatments was
$16 \mathrm{~h}$ per day. Embryo swelling was defined as an increase in size of at least twice its original size and the formation of a protocorm. The numbers of swollen embryos and the diameters of the embryos were recorded at 4-week intervals by examining under a microscope.

Statistical analysis

All data were expressed as means \pm standard error (SE) and subjected to analysis of variance (ANOVA). Each experiment was conducted in triplicate, with at least 200 seeds per replicate. Significant differences among the treatments were determined using Duncan's multiple range test at $\mathrm{P}$ $<0.05$ (SAS, 2003).

\section{Results and discussions}

$\mathrm{NaOCl}$ treatment and culture medium condition for seed germination

The effect of $\mathrm{NaOCl}$ pre-treatment on seed germination was examined. After $30 \mathrm{~min}$ of $1 \% \mathrm{NaOCl}$ treatment, the seed coat was completely bleached and the zygotic embryos inside of seed coats could be clearly seen (Fig. 1A). Swollen embryos were first scored 4 weeks after sowing (Fig. 1B). After $\mathrm{NaOCl}$ pretreatment, the frequency of embryo swelling was observed after 8 weeks of culture. The highest rate of swelling of zygotic embryos was observed in 30 min with $1 \% \mathrm{NaOCl}$ in POM medium (Table 1). The rate of embryo swelling in POM medium (90.7\%) was significantly greater than that in SGM medium (60.4\%). When untreated (without $1 \% \mathrm{NaOCl}$ ) immature seeds of $O$. patens, were cultured in SGM and POM medium, the rate of swelling was $38 \%$ and $29 \%$, respectively, after 4 weeks of culture (Table 1). After 8 weeks of culture of the mature seeds in $\mathrm{POM}$ medium without $\mathrm{NaOCl}$ treatment, the rate of protocorm formation was very low compared to the seeds treated with $\mathrm{NaOCl}$ (Table 1). In contrast, immature seeds subjected to $\mathrm{NaOCl}$ pre-treatment showed signs of swelling within 8 weeks of culture (Fig. 1C). NaOCl pretreatment of seeds in POM medium showed a significantly higher rate of protocorm formation compared to that of the immature seeds. The rate of protocorm formation in immature seeds was $58.8 \%$ after 8 weeks of culture (Table 1). The maximum rate of protocorm formation with a pretreatment of $1 \% \mathrm{NaOCl}$ for 30 min and culturing in POM medium was $87.5 \%$. The morphological development from seed to protocorm in $O$. patents was documented 


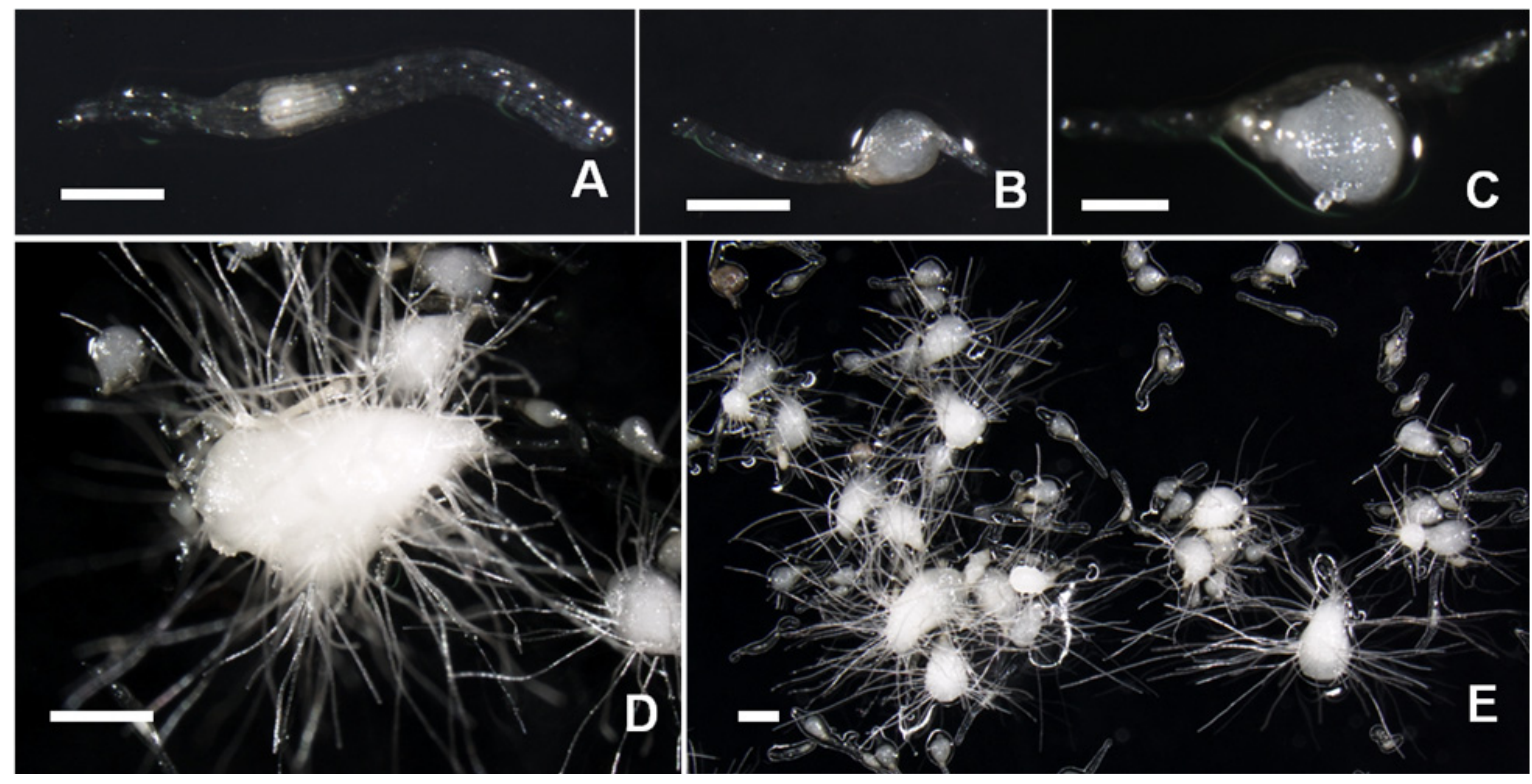

Fig. 1 Developmental stages of seed culture for O. patens. A: Hyaline embryo, testa intact (scale bar, $0.1 \mathrm{~mm}$ ), B: Embryos swollen (scale bar, $0.1 \mathrm{~mm}$ ), C: Swelled embryos present rhizoids (scale bar, $0.1 \mathrm{~mm}$ ), D: Closed view appearance of protomeristem and rhizoids elongation (scale bar, $1.0 \mathrm{~mm}$ ), E: Appearance of protomeristem and rhizoids elongation (scale bar, $1.0 \mathrm{~mm}$ )

Table 1 Effect of $\mathrm{NaOCl}$ treatment time for embryo swelling and protocorm formation of $O$. patens seeds after 8 weeks culture on medium supplemented with sucrose $(20 \mathrm{~g} / \mathrm{L})$ and gerlite $(3.0 \mathrm{~g} / \mathrm{L})$

\begin{tabular}{|c|c|c|c|c|}
\hline \multirow{2}{*}{$\begin{array}{c}\mathrm{NaOCl} \\
\text { treatment (min) }\end{array}$} & \multicolumn{2}{|c|}{ Swelled embryos formation (\%) } & \multicolumn{2}{|c|}{ Protocorm formation (\%) } \\
\hline & SGM & POM & SGM & POM \\
\hline 0 & $38.6 \pm 8.1 * b$ & $29.1 \pm 5.3 * b$ & $26.2 \pm 4.4 b$ & $10.8 \pm 3.5^{*} \mathrm{~b}$ \\
\hline 30 & $60.4 \pm 6.1 \mathrm{a}$ & $90.7 \pm 3.4 \mathrm{a}$ & $35.3 \pm 4.3 \mathrm{a}$ & $58.8 \pm 2.2 \mathrm{a}$ \\
\hline
\end{tabular}

*Data are the means $\pm \mathrm{SD}$, of three experiments. Different alphabetical letters are significantly different according to Duncun's multiple range test at $\mathrm{P}<0.05$. SGM and POM means Seed Germination Medium and Phytomax Orchid Mainterence Medium.

(Figs. 1D-E). The biggest embryo diameters were observed in seeds treated with $1 \% \mathrm{NaOCl}$ for $30 \mathrm{~min}$ and cultured in POM medium (Fig. 2D); these were followed by seeds cultured in SGM (Fig. 2C), and those not treated with $\mathrm{NaOCl}$ and cultured in SGM (Fig. 2A). On the other hand, seeds not treated with $\mathrm{NaOCl}$ and cultured in POM (Fig. 2B) showed the smallest embryo diameters. Seed germination of orchid species is typically very low or nonexistent in ex vitro and in vitro conditions (Ault and Blackmon 1987; Anderson 1996). Terrestrial orchids have more stringent requirements for germination, and information on the specific requirements for each species is limited (Fast 1982). NaOCl is a disinfecting agent that has been widely used for seed surface sterilization (Bewley and Black 1994; Miyoshi and Mii 1998). This reagent is also known to induce seed germination or overcome seed dormancy in some species (Vujanovic et al. 2000). In Cypripedium macranthos, the frequency of germination was $67 \%$ after sterilization with $\mathrm{NaOCl}$ (Miyoshi and Mii 1998). Yildiz and Celal (2002)
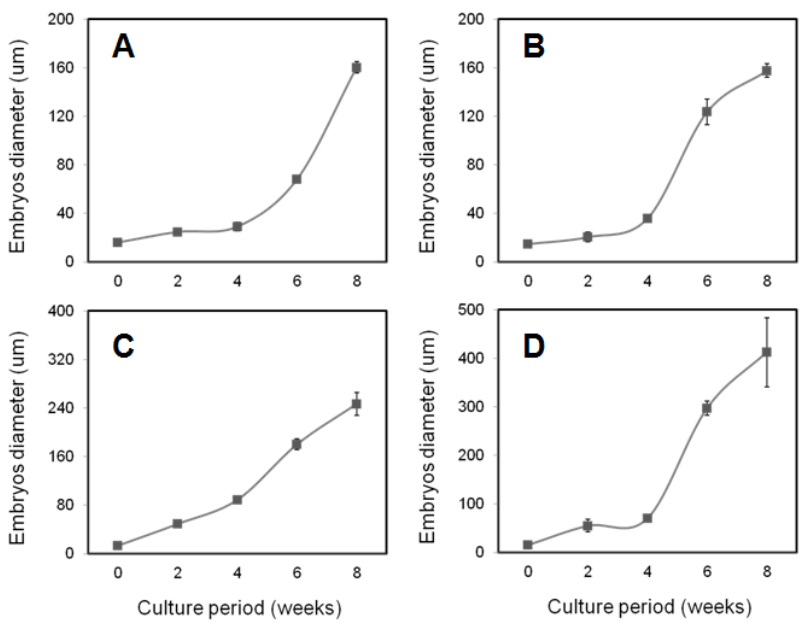

Fig. 2 Effects of culture media and $\mathrm{NaOCl}$ pre-treatment on frequency of embryos diameter after $0,2,4,6$ and 8 weeks in vitro culture. A: Non treated $\mathrm{NaOCl}$ for seeds on SGM, B: Non treated $\mathrm{NaOCl}$ for seeds on POM, C: $\mathrm{NaOCl}$ treated for 30 min on SGM, D: $\mathrm{NaOCl}$ treated for $30 \mathrm{~min}$ on POM. Vertical bars indicate standard errors $(n=3)$ 
previously reported that the pre-treatment of Linum usitatissimum seeds with $\mathrm{NaOCl}$ for 20 min enhanced its germination. The induction of germination through $\mathrm{NaOCl}$ treatment is thought to be due to scarification of the seed coat, which facilitates water and oxygen absorption or enhances oxidative respiration by producing more oxygen through the decomposition of $\mathrm{NaOCl}$ (Vujanovic et al. 2000). The effectiveness of disinfection solutions such as $\mathrm{NaOCl}$ and $\mathrm{Ca}(\mathrm{ClO})_{2}$ in stimulating the germination for orchid seeds has been reported in other species (Miyoshi and Mii 1998; St-Arnaud et al. 1992; Malmgren 1996), however, its mechanism has not yet been established. Possible mechanisms of action underlying the induction of seed germination or cessation of dormancy by $\mathrm{NaOCl}$ might include partial degradation of the seed coat and/or the solubilization and oxidation of certain growth inhibitors. Harvais (1982) interpreted the stimulatory effect of surface sterilization with $\mathrm{NaOCl}$ as a physiological effect of washing away the endogenous inhibitor, abscisic acid (ABA), from the seeds.
$\mathrm{NaOCl}$ and light source condition for embryo swelling and seed germination

The rate of embryo swelling after 4 weeks of sowing was 88.4, 90.6, and 54.2\% under white, red, and blue LED -lights, respectively, in POM medium (Table 2). The 625 $\mathrm{nm}$ wavelength (red LED-light) was associated with the highest rate of embryo swelling, although this also strongly inhibited protocorm formation (Table 2, Fig. 3B) after 8 weeks of culture. The highest rate of protocorm formation was observed in seeds treated with $1 \% \mathrm{NaOCl}$ for $30 \mathrm{~min}$ and cultured under red LED -light, followed by white -light (91.8\%, Fig. 3A), and blue LED -light (61.7\%, Fig. $3 \mathrm{C})$. On the other hand, the treatment without $\mathrm{NaOCl}$ in POM medium under white, red, and blue LED -lights was the least effective for protocorm formation (Table 2, Figs. 3D-F). The induction of embryo swelling, seed germination, and protocorm growth by using LEDs has also been previously reported in Calanthe satsuma (Fukai et al. 1997). The inhibition of seed germination by lighting has been

Table 2 Effect of $\mathrm{NaOCl}$ treatment time and light source (LED) for embryo swelling and protocorm formation of $O$. patens seed after 10 weeks culture on medium supplemented with sucrose $(20 \mathrm{~g} / \mathrm{L})$ and gerlite $(3.0 \mathrm{~g} / \mathrm{L})$

\begin{tabular}{|c|c|c|c|c|c|c|}
\hline \multirow{2}{*}{$\begin{array}{l}\mathrm{NaOCl} \text { treatment } \\
(\mathrm{min})\end{array}$} & \multicolumn{3}{|c|}{ Swelled embryos formation (\%) } & \multicolumn{3}{|c|}{ Protocorm formation $(\%)$} \\
\hline & White & LED Red & LED blue & White & LED Red & LED Blue \\
\hline 0 & $8.1 \pm 1.6^{*} b$ & $11.9 \pm 2.4 * b$ & $4.1 \pm 2.1 * b$ & $14.6 \pm 2.1 b$ & $12.8 \pm 2.8^{*} \mathrm{~b}$ & $6.4 \pm 1.1^{*} \mathrm{~b}$ \\
\hline 30 & $88.4 \pm 8.9 \mathrm{a}$ & $90.9 \pm 4.8 \mathrm{a}$ & $54.2 \pm 7.1 \mathrm{a}$ & $91.8 \pm 4.9 \mathrm{a}$ & $94.1 \pm 4.4 \mathrm{a}$ & $61.7 \pm 3.5 \mathrm{a}$ \\
\hline
\end{tabular}

*Data are the means $\pm \mathrm{SD}$, of three experiments. Different alphabetical letters are significantly different according to Duncun's multiple range test at $\mathrm{P}<0.05$.
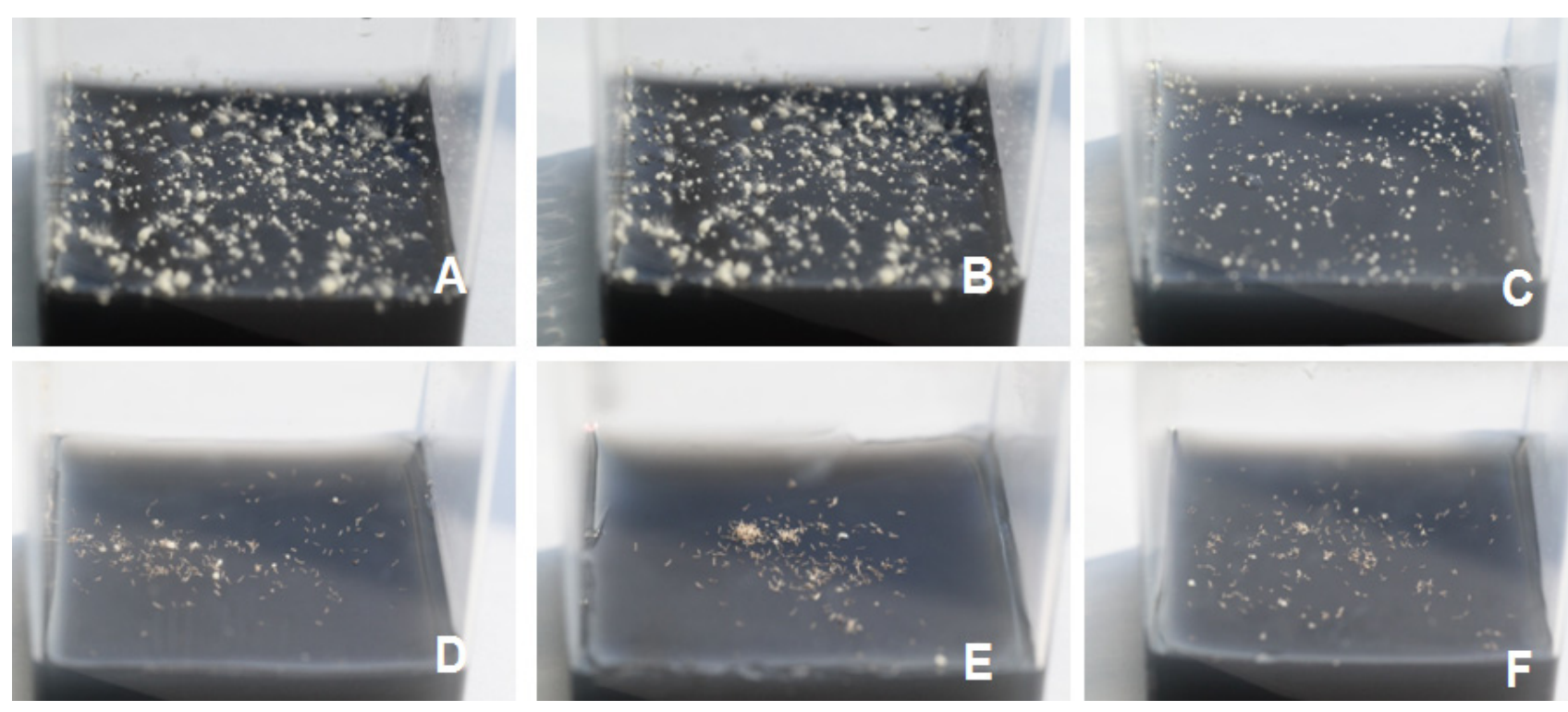

Fig. 3 Effects of light-LEDs for protocorms formation of $O$. patens seeds. A: White light on seed treated by $1 \% \mathrm{NaOCl} 30 \mathrm{~min}$, B: LED Red light on seed treated by $1 \% \mathrm{NaOCl} 30 \mathrm{~min}$, C: LED Blue light on seed treated by 1\% NaOCl $30 \mathrm{~min}, \mathrm{D}$ : White light on seed non-treated by $\mathrm{NaOCl}$, E: LED Red light on seed non-treated by $\mathrm{NaOCl}, \mathrm{F}$ : LED Blue light on seed non-treated by $\mathrm{NaOCl}$ 
reported for many terrestrial orchid species, such as Calanthe tricarinata (Godo et al. 2010) and Habenaria macroceratitis (Stewart and Kane 2006a). LED lighting systems also regulate in vitro seed germination and seedling growth. In Bletilla ochracea, a maximum seed germination of $74 \%$ was obtained using LEDs (Godo et al. 2011).

In conclusion, we demonstrate that embryo swelling occurs after immature seeds are subjected to $\mathrm{NaOCl}$ pre-treatment, thus resulting in a higher frequency of seed germination in $O$. patens. This protocol could be very useful for commercial nurseries that conduct large-scale propagation and ex situ conservation of $O$. patens.

\section{Acknowledgement}

This works was supported by Grant no. NIBR 2013-01-020 from the National Institute of Biological Resources in Korea.

\section{References}

Anderson AB (1996) The re-introduction of Platanthera ciliaris in Canada. In: Allen C. (Ed.). Proceedings of the North American Native Terrestrial Orchids: Propagation and Production. North American Native Terrestrial Orchid Conference, Maryland: 73-76

Ault JR, Blackmon WJ (1987) In vitro propagation of Ferocactus acanthodes (Cactaceae). Hort Sci 22:126-127

Bae KH, Choi YE (2013) Factors affecting fruit baring in natural habitat and in vitro culture of zygotic embryos of Cypripedium japonicum. Prog Ornamet Plant 11:146-152

Bae KH, Kim CH, Sun BY, Choi YE (2010) Structural changes of seed coats and stimulation of in vitro germination of fully mature seeds of Cypripedium macranthos Swartz by $\mathrm{NaOCl}$ pretreatment. Prog Ornament Plant 10:107-113

Bae KH, Ko MS, Lee MH, Kim NY, Song JM, Song G (2013) Effects of $\mathrm{NaOCl}$ treatment on in vitro germination of seeds of a rare endemic plant, Oreorchis coreana Finet. J Plant Biotech 40:43-48

Bae KH, Kwon HK, Choi YE (2009) In vitro germination and plantlet conversion from the culture of fully mature seeds of Cypripedium guttatum Swartz. Prog Ornament Plant 9: 160-165

Bewley JD, Black M (1994) Seeds: Physiology of development and germination. Second Edition. New York, Prenum Press

Bula RJ, Morrow RC, Tibbitts TW, Barta DJ, Ingnatius RW, Martin TS (1991) Light-emitting diodes as a radiation source for plants. Hort Sci 26:203-205

Dutra D, Kane ME, Richardson L (2009) Asymbiotic seed germination and in vitro seedling development of Cyrtopodium punctatum: a propagation protocol for an endangered Florida native orchid. Plant Cell Tiss Org Cult 96:235-243

Fast G(1982) European terrestrial orchids. Symbiotic and asymbiotic methods. In: Arditti J, ed. Orchid biology-reviews and perspectives II. Ithaca, NY: Comstock Publishing Associates, 326-329

Fukai S, Fujikawa K, Okamoto K, Hasegawa A, Goi M. (1997) Effects of red and blue light on germination and protocorm growth of Calanthe satsuma. Lindleyana 12:169-171

Godo T, Fujiwara K, Guan K, Miyoshi K (2011) Effect of wavelength of LED-light on in vitro asymbiotic germination and seedling growth of Bletilla ochracea (Orchidaceae), Plant Biotechnol 28:397-400

Godo T, Komori M, Nakaoki E, Yukawa T, Miyoshi K (2010) Germination of mature seeds of Calanthe tricarinata Lindl., an endangered terrestrial orchid, by asymbiotic culture in vitro. In Vitro Cell Dev Biol Plant 46:323-332

Harvais G (1982) An improved culture medium for growing the orchid Cypripedium reginae axienically. Can J Bot 51: 327-332

Harvais G, Hadley G (1967) The relation between host and endophyte in orchid mychorriza. New Phytol. 66:205-215

Hoenecke ME, Bula RJ, Tibbitts TW (1992) Importance of blue photon levels for lettuce seedlings grown under red-light emitting diodes. Hort Sci 27:427-430

Lee JS, Choi BH (2006) Distribution and red data of wild orchids in the Korean Peninsula. Kor J Plant Taxon 36:335-360

LeeYN (2006) Flora of Korea. Gyohaksa, Seoul

Malmgren S (1996) Orchid propagation: theory and practice. In: Allen, C. (Ed.), Proceedings of the North American Native Terrestrial Orchids: Propagation and Production. North American Native Terrestrial Orchid Conference, Maryland, pp63-71

Miyoshi K, Mii M (1998) Stimulatory effects of sodium and calcium hypochlorite, pre-chilling and cytokinins on the germination of Cypripedium macranthos seed in vitro. Physiol Plant 102:481-486

SAS Institute Inc (2003) SAS version 9.0. SAS Institute, North Carolina

Schuerger AC, Brown CS (1994) Spectral quality may be used to alter plant disease development in CELSS. Adv Space Res 14: 395-398

Stewart SL, Kane ME. (2006a) Asymbiotic germination and in vitro seedling development of Habenaria macroceratitis (Orchidaceae), a rare Florida terrestrial orchid. Plant Cell Tiss Org Cult 86:147-158

Stewart SL, Kane ME (2006b) Symbiotic germination of Habenaria macroceratitis (Orchidaceae), a rare Florida terrestrial orchid. Plant Cell Tiss Org Cult 86:159-167

Stewart SL, Kane ME (2007) Symbiotic seed germination and evidence for in vitro mycobionts specificity in Spiranthes brevilabris (Orchidaceae), and its implications for species-level conservation. In Vitro Cell Dev Biol Plant 43:178-186

St-Arnaud MD, Lauzer D, Barabe D (1992) In vitro germination and early growth of seedlings of Cypripedium acaule (Orchidaceae). Lindleyana 7:22-27 
Suzuki RM, Moreira VC, Nakabashi M, Ferreira VM (2009) Estudo da germinação e crescimento in vitro de Hadrolaelia tenebrosa (Rolfe) Chiron \& V.P. Castro (Orchidaceae), uma espécie da flora brasileira ameaçada de extinção. Hoehnea 36: 657-666

Tennessen DJ, Singsaas EL, Sharkey TD (1994) Light-emitting diodes as a light source for photosynthetic research. Photosynt Res 39:85-92

Tripathy BC, Brown CS (1995) Root-shoot interaction in the greening of wheat seedlings grown under red light. Plant Physiol 107:407-411

Vujanovic, V, St-Arnaud M, Barabe D, Thibeault G (2000) Viability testing of orchid seed and the promotion of colouration and germination. Ann Bot 86:79-86

Yildiz M, Celal ER (2002) The effect of sodium hypochlorite solution on in vitro seedling growth and shoot regeneration of flax (Linum usitatissimun). Natul wissen Schffen 89:259-261 